\title{
Perfil e práticas de saúde bucal do agente comunitário de saúde em municípios piauienses de pequeno porte
}

\author{
Profile and procedures of the community health agents \\ regarding oral health in the countryside of Piauí State, Brazil
}

M arcoeli Silva de M oura ${ }^{1}$

Claro Joséde Carvalho ${ }^{2}$

José Tadeu Cavalcante de Amorim ${ }^{2}$

M aurílio Francisco Soares Siqueira M arques ${ }^{2}$

Lúcia de Fátima Almeida de Deus M oura ${ }^{1}$

Regina Ferraz $M$ endes $^{3}$

${ }^{1}$ Departamento dePatologia eClínica Odontológica, Centro deCiências da Saúde, UniversidadeFederal do Piauí. Campusdalninga. 64049-550 Teresina PI . marcoeli-moura@uol.com.br ${ }^{2}$ Curso de Especialização em Odontologia em Saúde Coletiva, Universidade Federal do Piauí.

${ }^{3}$ Departamento de Odontologia Restauradora, UniversidadeFederal do Piauí.
Abstract The aim of this survey was to draw the demographic profile and the actions concerning oral health carried out by the communitarian agents of health, in small towns of Piauí State, Brazil. Four towns were chosen: Água Branca, Piracuruca, Queimada Nova eSimões. Themethod used was observational descriptive cross-sectional. 0 nehundred and nineagents were assessed through questionnaires, with 28 multiples choice questions. Data was analyzed in Excel. It was possible to conclude that: the communitarian agents on the countryside of Piauí are predominantly females, married, age between 20-39, with one to three children, nine years of formal education, monthly income of one minimum salary, and has been living in their community for 24 years in average; the large majority of the agents has not received specific qualification to carry out their job, has not attended lectures on oral health, although almost half of them works on activities related to oral health, despite not registering them properly; they perceive themsel ves as having a fair knowledge of oral health, which coincided with the assessment collected by the questionnaire. Key words Communitarian agents of health, Oral health promotion, Family $\mathrm{H}$ ealth Program, U nified $\mathrm{H}$ ealth System
Resumo 0 objetivo desta pesquisa foi traçar o perfil demográfico e práticas de saúde bucal do ACS, em cidades de pequeno porte do Estado do Piauí. Foram selecionados quatro municípios: Água Branca, Piracuruca, Queimada N ova e Simões. 0 método utilizado foi o transversal observacional descritivo. Foram aplicados questionários a 109 ACS, constituídos de 28 perguntas fe chadas. Os dados foram transferidos para planiIha do programa Excelò, tabulados e analisados. Pelos dados obtidos, foi possível concluir que: (1) o agentecomunitário de saúde do interior do Piauí é predominantemente do sexo feminino, casado, com idadeentre 20-39 anos, tem em média de um a três filhos, com grau de escolaridade médio acima de nove anos, renda de um salário mínimo, residindo em média há 24 anos na comunidade; (2) a grande maioria dos ACS não foi capacitada, não assistiu palestras educativas sobre saúde bucal; entretanto, quase a metade realiza atividades em saúde bucal, mas não as registra; (3) a autopercepção sobre o conhecimento em saúde bucal pelos ACS predominou entre conceitos regular e bom, o que coincidiu com o percentual de acertos ao questionário aplicado.

Palavras-chave Agente comunitário de saúde, Promoção desaúdebucal, Programa Saúdeda Família, SUS 
Introdução

O Sistema Ú nico de Saúde(SUS), institucionalizado pela constituição de 1988, determinou mudanças significativas e decisivas no modelo de atenção à saúde exercido até então. Práticas de prevenção e promoção de saúde, baseadas em atividades prioritariamente coletivas, substituiriam aquelas centradas no modelo de caráter curativo, na medicalização e hospitais.

A criação do SUS foi uma conquista de profissionais de saúde al iados à sociedade civil organizada e poder público, em defesa de saúde com qualidade para a população brasileira. Esse sistema, com seus princípios de equidadee participação popular, éum modelo democrático que deve ser aperfeiçoado e defendido.

Neste contexto, um profissional assume um papel de destaque- 0 agentecomunitário de saúde (ACS). Em 1991, o M inistério da Saúde criou - Programa de Agentes Comunitários de Saúde (PACS), uma das primeiras estratégias para a reorganização da atenção à saúde, como medida de enfrentamento aos graves índices de morbimortalidade materna e infantil, visando contribuir para uma melhor qualidade de vida, investindo maciçamente na educação em saúde ${ }^{1,2}$. 0 ACS tem um papel fundamental na orientação das famílias, no encaminhamento dos proble mas, poiséo elemento da equipequerealiza vigilância à saúde, elo entre as famílias, comunidades e a Unidade de Saúde ${ }^{3}$. A o percorrer as casas para cadastrar as famílias e identificar os seus problemas de saúde, os ACS contribuem para que os serviços possam oferecer uma assistência mais voltada para a família, de acordo com a realidade e os problemas de cada comunidade ${ }^{2,4}$.

No Piauí, o PACS foi implantado, neste mesmo ano, em 46 municípios, 38,6\% dos municípios existentes no período (119), com 1.306 ACS $^{5}$.

O Programa Saúde da Família (PSF), criado em 1994, foi fundamental para a organização da atenção básica, no primeiro nível de atenção à saúde. É uma estratégia do SUS que deve estar em consonância com seus princípios ediretrizes. O território, a população adstrita, o trabalho em equipe, a intersetorialidade constituem eixosfundamentais de sua concepção e as visitas domiciliares, uma de suas principais estratégias, objetivam ampliar o acesso a serviços e criar vínculos com a população $0^{4}$.

A Estratégia de Saúde da Família deixou de ser vista como um simples programa e passou a ser considerada como reorientadora e estruturante da organização do SUS a partir de 1997, através da Portaria n 1.886/GM /M S. Atualmente, éformada pelos dois programas anteriormente descritos - PACS e PSF 6 .

Em 10 de julho de 2002, foi criada a profissão deAgenteComunitário de Saúde (Lei o 10.507). Cabe destacar na lei que as ações dos ACS dar-seão exclusivamente no âmbito do Sistema Único deSaúde (SUS), realizando atividades de prevenção de doença e promoção da saúde nos domicílios e espaços comunitários (Art. 1ํ). Como requisitos, o agente de saúdeterá queresidir naárea da comunidade, ter concluído com aproveitamento curso de qualificação básica para sua formação e cursado o ensino fundamental (Art. 30) ${ }^{7}$.

Em 2001, foi publicada a Portaria № 267, com o objetivo de ampliar o acesso da população às ações de saúde bucal, incluindo-as no conjunto de atividades desenvolvidas pelo Programa SaúdedaFamília, respeitando os seus princípiosorganizativos e operacionais $s^{8}$. Atualmente, o PSF está implantado nos 223 municípios do estado do Piauí, com 1.002 equipes desaúdedafamília (ESF), 774 equipes de saúde bucal (ESB) e 6.296 ACS 5 .

Para a saúde bucal, esta nova forma de se fazer ações cotidianas representa ao mesmo tempo um avanço significativo eum grande desafio. Obteviram-se ganhos no campo do trabalho em equipe, melhorias nas relações com o usuário, incrementos nas medidas de caráter coletivo e modificações da gestão, implicando uma nova forma de se produzir cuidado em saúde bucal ${ }^{9}$.

Um dos grandes desafios da odontologia na atualidade, que historicamente construiu suas práticasindividualizadas e centradas na figura dos cirurgiões-dentistas, édeslocar o foco da atenção centrada na doença para a formulação de estraté gias pautadas na promoção da saúde, que busquem dar respostas adequadas à demanda nas situações de agravo, aliada a uma definição de prioridades e de organização para esta demanda com ênfase na abordagem integral dos usuários, tornando-os sujeitos das ações de saúde?.

A saúde bucal, parte integrante da saúde geral dos indivíduos, configura-se de primordial relevância para que os agentes de saúde dominem seus conhecimentos básicos visando à promoção, prevenção e recuperação na microárea de atuação. Estetrabalho tevepor objetivo analisar o perfil demográfico e práticas de saúde bucal desenvolvidas por agentes comunitários de saúde (ACS) em municípios piauienses de pequeno porte. 


\section{Material e método}

0 método utilizado foi o transversal observacional descritivo. A pesquisa foi aprovada no Comitê de Ética em Pesquisa da Universidade Federal do Piauí, seguindo os preceitos da Resolução $n^{\circ}$ 196/96 do Conselho N acional de Saúde, e os ACS que aceitaram participar da pesquisa assinaram o termo de consentimento livree esclarecido previamente ao preenchimento do questionário.

A pesquisa foi realizada no interior do Estado do Piauí, nos municípios de Água Branca, Piracuruca, Queimada-Nova, e Simões, perfazendo um total de 109 agentes de saúde/17 equipes desaúde bucal (16/6, 43/620/1 e30/4, respectivamente), analisando-seindividual mentecadaACS, no período de fevereiro a maio de 2006.

Foi realizado, primeiramente, um pré-teste para adequação do instrumento de coleta de dados utilizado, aferição das dificuldades encontradas e capacitação dos pesquisadores envolvidos no projeto. Uma parte da amostra ( $10 \%$ do total dos ACS) participou deum teste piloto com a finalidade de verificar o grau de dificuldade e entendimento em relação às perguntas fechadas do questionário, conservando ou alterando-as, como forma de adequação.

0 questionário foi constituído de 28 perguntas fechadas, contendo, na primeira parte, questões sobre o perfil dos ACS, visitas domiciliarese sua periodicidade, quais as orientações que estão sendo repassadas para melhorar a saúde bucal da comunidadee, na segunda, foram testados os conhecimentos a respeito da saúde bucal. N essa parte, foi elaborado um questionário contendo dez questões de múltipla escolha, abordando assuntos básicos de saúde bucal que deveriam fazer parte do cotidiano do ACS. Cada questão poderia ter mais de uma alternativa correta, totalizando 26 acertos. Para tabular os dados, inicialmente foram somadas as respostas corretas e o conhecimento em saúde bucal categorizado entre ruim (um a seis acertos), regular (sete a treze acertos), bom (catorze a dezenove acertos) eótimo (vinte a 26 acertos).

Os dados foram transferidos para planilha

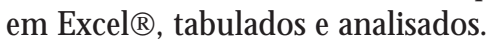

\section{Resultados}

Os resultados estão dispostos nas tabelas 1 a 4.
Tabela 1. Perfil da população avaliada. UFPI, 2006.

\begin{tabular}{|c|c|c|}
\hline Característica & Frequência & $\%$ \\
\hline \multicolumn{3}{|l|}{ Gênero } \\
\hline M asculino & 20 & 18,3 \\
\hline Feminino & 89 & 81,7 \\
\hline \multicolumn{3}{|l|}{ Idade } \\
\hline$<20$ anos & 1 & 0,92 \\
\hline 20-29 anos & 31 & 8,44 \\
\hline 30-39 anos & 52 & 7,71 \\
\hline 40-49 anos & 16 & 4,7 \\
\hline mais de 50 anos & 9 & 8,3 \\
\hline \multicolumn{3}{|l|}{ Estado civil } \\
\hline Casado & 66 & 60,6 \\
\hline Solteiro & 35 & 32,1 \\
\hline Divorciado & 1 & 0,9 \\
\hline Viúvo & 2 & 1,8 \\
\hline Outros & 5 & 4,6 \\
\hline \multicolumn{3}{|l|}{ Número de filhos } \\
\hline 0 & 24 & 22 \\
\hline 1 & 22 & 20,2 \\
\hline 2 & 26 & 23,9 \\
\hline 3 & 15 & 13,7 \\
\hline 4 & 9 & 8,3 \\
\hline 5 & 5 & 4,6 \\
\hline $6-8$ & 8 & 7,3 \\
\hline \multicolumn{3}{|l|}{ Anos de estudo formal } \\
\hline Abaixo de 8 anos de estudo formal & 20 & 18,3 \\
\hline 1-4 anos & 13 & 11,9 \\
\hline 5-8 anos & 21 & 19,3 \\
\hline 9-11 anos & 49 & 45 \\
\hline mais de 12 anos & 26 & 23,8 \\
\hline \multicolumn{3}{|l|}{ Renda familiar } \\
\hline$<1 \mathrm{SM}$ & 13 & 11,9 \\
\hline $1 \mathrm{SM}$ & 79 & 72,5 \\
\hline $1-3 \mathrm{SM}$ & 10 & 9,2 \\
\hline mais de $3 \mathrm{SM}$ & 3 & 2,7 \\
\hline $\mathrm{N}$ ão respondeu & 4 & 3,7 \\
\hline \multicolumn{3}{|l|}{ Tempo que reside na comunidade } \\
\hline \multicolumn{3}{|l|}{ Variação de 1 a 59 anos } \\
\hline \multicolumn{3}{|l|}{ M édia - 24, 6 anos } \\
\hline \multicolumn{3}{|l|}{ Tempo que atua como ACS } \\
\hline 1-2 anos & 9 & 8,3 \\
\hline 3-4 anos & 1 & 0,95 \\
\hline 5-7 anos & 57 & 2,3 \\
\hline 8-10 anos & 10 & 9,2 \\
\hline mais de 10 anos & 27 & 24,8 \\
\hline Não respondeu & 5 & 4,5 \\
\hline \multicolumn{3}{|l|}{ Número de visitas diárias } \\
\hline \multicolumn{3}{|l|}{ Variação - 4 a 20} \\
\hline \multicolumn{3}{|l|}{ M édia - 8,7 } \\
\hline \multicolumn{3}{|c|}{ Número de famílias pelas quais é responsável } \\
\hline \multicolumn{3}{|l|}{ Variação - 15 a 290 famílias } \\
\hline M édia - 111,6 famílias & & \\
\hline
\end{tabular}

Fonte: Pesquisa direta. 
Os agentes comunitários de saúde avaliados são, em sua maioria, do sexo feminino, entre 2039 anos, casados, possuem de um a três filhos, com grau de escolaridade exigido pela Lei $n$ 10.507/2002, renda de um salário mínimo, residindo em média 24 anos na comunidade, realizam em média oito visitas diárias e assistem em média 111,6 famílias.

A maioria dosagentes desaúdenão foi capacitada, nem assistiu palestras educativas sobre saúde bucal; entretanto, quase a metade dos entre vistados realiza atividades em saúde bucal, embora não as registre em mapas de produtividade.

A autopercepção sobre o conhecimento em saúde bucal pelos ACS predominou entre conceitos regular e bom, coincidindo com o percentual de acertos ao questionário.

Quase a totalidade da amostra demonstrou ter dificuldades em desempenhar funções relativas a orientações sobre saúde bucal na comunidade, apesar de considerar a função como parte de suas atribuições.

Tabela 2. Capacitação e atividades em saúde bucal realizadas. UFPI, 2006.

\begin{tabular}{lcc}
\hline & Frequência & $\%$ \\
\hline Capacitação para o Programa de Saúde Bucal & & \\
Sim & 22 & 20,2 \\
N ão & 87 & 79,8 \\
Assistiu palestra educativa sobre saúde bucal & & \\
Sim & 44 & 40,45 \\
N ão & 65 & 59,6 \\
Realiza atividade de saúde bucal & & \\
Sim & 50 & 45,9 \\
N ão & 59 & 54,1 \\
Quais atividades realiza na comunidade & & \\
N ão realiza & 59 & 54,1 \\
Educação em saúde bucal & 26 & 23,8 \\
Orientação para bebês & 43 & 39,4 \\
Orientação para gestantes & 44 & 40,4 \\
Escovação supervisionada & 16 & 14,7 \\
A plicação de flúor & 14 & 12,8 \\
Faz registro das atividades & & \\
Sim & 10 & 9,2 \\
Não & 99 & 90,8
\end{tabular}

Fonte: Pesquisa direta.

\section{Discussão}

Os ACS são os membros da equipe de saúde que atuam em maior proximidade com a comunidade edesempenham relevantepapel como veículo multiplicador deconhecimentos einformações, mediando 0 saber popular e o técnico-científico ${ }^{10}$. Em face de sua ligação com a comunidade onde atua, - ACS imprime novas cores ao fazer saúde e, em especial, ao fazer saúde pública e coletiva ${ }^{11}$.

A visita domiciliar, realizada pelo ACS, possibilita a descoberta de causas "distais" (saneamento, educação, moradia, trabalho, nutrição, lazer, etc.) nas cadeias do processo saúde-doença que influenciam na saúde bucal dos indivíduos, em virtude de permitir a visual ização defatores sociais efamiliares no âmbito e contexto vivido pelos usuários ${ }^{12}$.

Os ACS que atuam em al guns municípios de pequeno porte no Estado do Piauí, avaliados neste estudo, apresentaram-se predominantemente do gênero feminino, faixa etária entre $20 \mathrm{e}$ 39 anos, casados, tendo em média de um a três filhos (Tabela 1), dados esses que coincidem com o perfil encontrado em outras localidades brasileiras ${ }^{3,13,14}$. Essas características apresentam-se favoráveis para 0 desenvolvimento das atividades realizadas, uma vez que, fazendo parte de uma estrutura familia e, em sua maioria mulheres, têm maior sensibilidade para entender elidar com os problemas da comunidade, por serem consideradas "cuidadoras" na sociedade.

Acredita-se que os agentes comunitários de saúde com mais idade tendem a conhecer meIhor a comunidade, ter mais vínculos e laços de amizades, porém podem ter algumas inimizades ou conflitos com outros moradores. Eles também têm seus próprios conceitos sobre o processo saúde-doença, advindos de experiências próprias ou al heias, podendo ser mais resistentes a novos conceitos relacionados à promoção da saúde em sua comunidade. Por outro lado, os agentes mais jovens não conhecem tão bem a comunidade, seu envolvimento pode ser menor; entretanto, poderão não ter inimizades, seus conceitos de saúde e doença poderão não ser muito arraigados, estando mais abertos às mudanças e às novidades ${ }^{14}$.

Em 1989, Giffin e Shiraiwa ${ }^{15}$ descreveram a implantação de um trabalho de atenção primária à saúde em favelas do Rio de Janeiro, no qual os agentes de saúde das comunidades atendidas trabalhavam dentro de um modelo operacional que incluía visitas domiciliares contínuas às famíliase trabalho em grupos demulheresegestantes. N essa 
Tabela 3. Conhecimento em saúde bucal do ACS. U FPI, 2006.

\begin{tabular}{|c|c|c|}
\hline & Frequência & $\%$ \\
\hline \multicolumn{3}{|l|}{ Como considera o seu conhecimento sobre saúde bucal } \\
\hline Ruim & 13 & 11,9 \\
\hline Regular & 52 & 47,7 \\
\hline Bom & 40 & 36,7 \\
\hline Ótimo & 4 & 3,7 \\
\hline \multicolumn{3}{|l|}{ Total de acertos relacionados ao conteúdo do questionário sobre saúde bucal } \\
\hline 1-6 - Ruim & 0 & 0 \\
\hline 7-13- Regular & 39 & 35,8 \\
\hline 14-19-Bom & 55 & 50,4 \\
\hline 20-26 - Ótimo & 15 & 13,8 \\
\hline \multicolumn{3}{|l|}{ O que causa cárie dentária } \\
\hline Respostas corretas & 39 & 35,8 \\
\hline Respostas que incluíam hereditariedade; dentes fracos e uso de antibiótico & 70 & 64,2 \\
\hline \multicolumn{3}{|l|}{ Gestante pode receber atendimento odontológico? } \\
\hline Sim & 102 & 93,6 \\
\hline Não & 3 & 2,7 \\
\hline Não sabe & 4 & 3,7 \\
\hline \multicolumn{3}{|l|}{ Higiene bucal de bebês } \\
\hline Respostas corretas & 96 & 88,1 \\
\hline \multicolumn{3}{|l|}{ Primeira visita do bebê ao dentista } \\
\hline Primeiro ano & 71 & 65,2 \\
\hline De 1 a 2 anos & 21 & 19,3 \\
\hline Depois de 2 anos & 14 & 12,8 \\
\hline Não sabe & 3 & 2,7 \\
\hline \multicolumn{3}{|l|}{ Cuidados com alimentação bebê } \\
\hline Resposta integralmente correta & 13 & 11,9 \\
\hline Combinações de respostas corretas & 96 & 88,1 \\
\hline \multicolumn{3}{|l|}{ Placa bacteriana } \\
\hline Resposta integralmente correta & 20 & 18,3 \\
\hline Combinações de respostas corretas & 89 & 81,7 \\
\hline \multicolumn{3}{|l|}{ Cuidados com as escovas dentais } \\
\hline Resposta integralmente correta & 28 & 25,7 \\
\hline Combinações de respostas corretas & 81 & 74,3 \\
\hline \multicolumn{3}{|l|}{ Sangramento gengival } \\
\hline Respostas corretas & 105 & 96,3 \\
\hline Respostas que incluíam "deixar de escovar quando há sangramento gengival" & 4 & 3,7 \\
\hline \multicolumn{3}{|l|}{ Cuidados com as próteses } \\
\hline Respostas corretas & 84 & 77,1 \\
\hline Respostas que incluíam "limpar com água fervente" & 25 & 22,9 \\
\hline \multicolumn{3}{|l|}{ Fatores précancerígenos } \\
\hline Respostas corretas & 2 & 1,8 \\
\hline $\begin{array}{l}\text { Respostas que incluíam próteses mal adaptadas / câmaras de sucção; } \\
\text { raízes residuais efatores irritativos }\end{array}$ & 107 & 98,2 \\
\hline
\end{tabular}

Fonte: Pesquisa direta.

proposta precursora do PACS, os agentes eram as próprias mães das favelas, pois possuíam a experiência vivida de criação defilhos, nas condições em que a clientela se encontrava.

A profissão agente comunitário de saúde foi criada no Brasil em 1991 eregulamentada por lei em 20027. Para exercer a função, énecessário que 0 indivíduo tenha ensino fundamental completo. Os resultados apresentados na Tabela 1 mostram que a maioria dos ACS apresenta nível de escolaridade superior àqueles exigidos pela lei. 0 estudo formal favorece ao ACS melhor capaci- 
Tabela 4. Dificuldade para o trabalho em saúde bucal. UFPI, 2006.

\begin{tabular}{lcr}
\hline & Frequência & $\%$ \\
\hline Há dificuldade para se trabal har saúde & & \\
bucal na comunidade? & & \\
$\quad$ M uita & 44 & 40,4 \\
Mais ou menos & 45 & 41,3 \\
Pouca & 14 & 12,8 \\
$\quad$ Nenhuma & 4 & 3,7 \\
$\quad$ Não sei & 2 & 1,8 \\
A educação em saúde bucal faz parte das & & \\
atribuições do ACS? & & \\
$\quad$ Sim & 10 & 99,1 \\
Não & 81 & 0,9 \\
\hline
\end{tabular}

Fonte: Pesquisa direta. tros integrantes da equipe de saúde, uma vez que o frequente contato com os usuários resulta em que esses costumam revelar aspectos de sua condição de saúde para o agente, muitas vezes associados a atos ilícitos ou moralmente reprováveis, criando um constrangimento ético para o ACS.

Quanto ao tempo de trabalho como ACS, encontrou-se trabalhadores com tempo de atuação considerável no programa, predominando o intervalo entre cinco a sete anos, com enquadramento de $52,3 \%$ da amostra, e ainda destaca-se $24,8 \%$ que já atuam há mais de dez anos como agente (Tabela 1). 0 tempo de permanência no programa é importante para o entendimento de seu papel, queéconstruído em suas práticas cotidianas ${ }^{14}$.

A visita domiciliar éuma das principais atividades preconizadas pelo M inistério da Saúde para o ACS $S^{1,2}$, poisépor meio dela queo agenteconhece melhor as necessidades das famílias e, principalmente, desenvolveo trabal ho educativo. 0 ACS avaliado realiza em média 8,7 visitas diárias, com variação de quatro a vinte. 0 M inistério daSaúde preconiza no mínimo oito visitas diárias, recomendação que na presente amostra foi acatada por $76,1 \%$ dos entrevistados. As orientações realizadas nas visitas domiciliares não estão prontas, pois cada casa representa uma real idade que possibilita uma troca de informações.

O ACS é responsável por 750 pessoas de sua comunidade, número esse flexível, pois depende das necessidades locais, deven do visitar cada domicílio pelo menos uma vez por mês². Neste estudo, os ACS são responsáveis por em média 111 famílias, com uma larga variação de quinzea 290, evidenciando realidades bastantediferentes.

Nos quatro municípios estudados, as equipes de saúde bucal são da modalidade I, composta por cirurgião-dentista (CD) e auxiliar de consultório dentário (ACD). Ações de promoção e prevenção individuais e coletivas são desenvolvidas nas Unidades Básicas de Saúde (UBS) e comunidade; entretanto, noventa por cento dessas ocorrem nas UBS, em virtude da grande demanda reprimida por assistência à saúde. Aproximadamente, um turno por semana é reservado para atividades coletivas nos espaços sociais e escolas.

A grande maioria dos agentes de saúde (79,8\%) não foi capacitada e não assi stiu a palestras educativas sobre saúde bucal (59,6\%). Apenas em dois dos municípios pesquisados houve uma capacitação com carga horária de vinte horas, porém os mesmos não se sentiam capacitados para informar à população sobre saúde bucal. Tal fato pode ter sido uma consequência 
da inserção tardia do cirurgião-dentista (CD) na equipe de saúde da família. Torna-se necessário o treinamento dos ACS para realizarem procedimentos técnicos em saúde bucal, como técnicas dehigiene bucal, detecção precoce decárie, doença periodontal e câncer bucal, entre outros, sob pena de comprometer a qualidade e efetividade das ações desenvolvidas ${ }^{10}$.

Embora um grande número de agentes não tenha sido capacitado para desenvolver atividadesligadas à saúde bucal, quase a metade $(45,9 \%)$ realiza tais atividades, mas não as registra. Apesar de não ter ocorrido um treinamento formal para os ACS, muitos CD integrantes da equipe estão repassando conhecimentos para os agentes que trabalham na sua equipe, fato comprovado pelas atividades realizadas: educação em saúde bucal, orientação para bebês e gestantes, escovação supervisionada e aplicação de flúor (Tabela 2).

Quando interrogados sobre a autopercepção em saúde bucal, a maioria $(84,4 \%)$ considerou 0 próprio conhecimento entre regular e bom (Tabela 3). Ao se analisar o total de acertos no questionário de saúde bucal, categorizados de ruim a ótimo, observa-se uma correspondência com os resultados acima citados: $86,2 \%$ ficaram classificados entre regular e bom, demonstrando um bom conhecimento básico de saúde bucal. Tais conhecimentos, apesar da mai oria não ter rece bido treinamento formal, podem ser resultado de saberes técnico-científicos já absorvidos, por diversas maneiras, seja pela presença em palestras, meios de comunicação ou treinamento dentro da própria equipe.

0 alto índice de respostas corretas com relação aos conteúdos tratamento odontológico na gravidez, higiene bucal dos bebês, cuidados com a alimentação dos bebês, conhecimento sobre placa bacteriana, cuidados com escovas dentais e conduta no sangramento gengival demonstraum bom conhecimento sobre conceitos básicos de saúde bucal. Todavia, destaca-se um percentual de 35\% que desconhece a importância da primeira visita ao bebê ao dentista no primeiro ano de vida ${ }^{18}$.

Pôde-se perceber em várias respostas a influência de crenças enraizadas no universo popular, fato esse já relatado por M israchi e Sáez ${ }^{19}$, que enfatizam a presença de valores ecrenças nas respostas dos agentes de saúde quando fazem a conexão entregestação eaumento de lesões decárie. No presente estudo, $64,2 \%$ dos ACS acreditam quea hereditariedade, dentes fracos euso deantibióticos são fatores predisponentes para a ocorrência da cárie dentária. A utilização de água fer- vente para limpeza de próteses dentárias foi relatada por $23 \%$ dos entrevistados e $98,2 \%$ consideram próteses mal adaptadas, câmaras de sucção e raízes residuais como fatores pré-cancerígenos.

Frazão e $M$ arque ${ }^{20}$ mostraram a influência da capacitação do ACS na percepção de saúde bucal de mulheres e mães. Passados doze meses após o treinamento dos agentes, o estudo captou significativas mudanças nos conhecimentos apresentados, tanto pelo grupo de ACS quanto pelo grupo de mulheres e mães, efeito que pode ser atribuído ao trabalho desse pessoal, realizado por meio de visitas domiciliares.

Analisando-se a Tabela 4, constata-se que, apesar de considerarem haver dificuldades em se trabalhar saúde bucal, os ACS mostram-se abertos a receber novos conhecimentos, poistêm conviç̧ão de que a saúde bucal faz parte de suas atribuições, conscientes que podem ser multiplicadores de conhecimentos, peças fundamentais para promover e prevenir as principais doenças bucais, melhorando a qualidade de vida da população. Essa dificuldadealegada pel os ACS pode ser em parte explicada pela observação de Silva e Dalmaso ${ }^{13}$, que relatam a relação do agente com a comunidade, por ser percebido e perceber como conhecedor da população, organizador do acesso ao serviço de saúde, vigilante dos riscose controlador da aderência aos cuidados propostos pelo médico eenfermeiro, mastampouco seidentificava com as ações de educação em saúde.

Nunes et al. ${ }^{10}$ relataram a importância dos agentes de saúde em criar estratégias para a implementação de ações educativas para a saúde, propondo mudanças dehábitos e comportamentos (alimentares, higiênicos e outros) que, em muitos casos, encontram, por parte da população, várias formas de resistência.

Os cirurgiões-dentistas integrantes das equipes de saúde devem compreender a importância que os agentes de saúde têm na resolução dos principais problemas da saúde bucal, seja orientando as famílias a realizar uma boa higi ene, controle da dieta, evitando a cárie dental e doença periodontal, ou na orientação para a deteç̧ão precoce do câncer bucal.

Para a área odontológica, o estímulo ao desenvolvimento de ações de promoção, proteção e educação se faz necessário, bem como a correspondente capacitação profissional, buscando ampliar, por meio do PSF, a conscientização da população quanto a essa importante questão da saúde ${ }^{16}$.

Ao conhecer melhor como se processa a relação saúde-doença bucal, os ACS poderão con- 
tribuir de modo ainda mais significativo para as ações de promoção, prevenção e recuperação da saúde desenvolvidas em cada ambiente familiar, através de visitas domiciliares, reuniões no posto de saúde com gestantes e idosos, etc. Assim, a possibilidade dessa maior contribuição deve ser fortemente reconhecida e explorada pelos profissionais queintegram a Equipe de Saúde Bucal.

\section{Conclusões}

O agente comunitário de saúde do interior do Piauí épredominantemente do gênero feminino, casado, com idade entre vinte e 39 anos, tem em média de um a três filhos, com grau de escolaridade acima de nove anos, renda mensal de um salário mínimo, residindo em média há 24 anos na comunidade.

A grande maioria dos ACS não foi capacitada, não assistiu a pal estras educativas sobre saúde bucal; entretanto, quase a metade realiza atividades em saúde bucal, mas não as registra.

A autopercepção sobre o conhecimento em saúde bucal pelos ACS predominou entreos conceitos regular ebom, o que coincidiu com o percentual de acertos ao questionário aplicado.

Quase a totalidade da amostra tem dificuldade para trabalhar saúde bucal na comunidade, apesar de considerá-la parte de suas atribuições.

\section{Colaboradores}

MS M oura, CJ Carvalho, JTC Amorim e M FSS $M$ arques participaram detodas as etapas do projeto e elaboração final do trabalho; LFAD M oura e RF M endes participaram da interpretação dos dados e redação do artigo.

\section{Agradecimentos}

Os autores agradecem o apoio das Secretarias M unici pais de Saúde dos municípios avaliados, a colaboração dos agentes comunitários de saúde e de $M$ arlene Damasceno de M oura Fé, aluna do curso de especialização O dontologia em Saúde Coletiva. 


\section{Referências}

1. Brasil. Ministério da Saúde. Normas e diretrizes do programa de agentes comunitários de saúde, PACS, Portaria 1886/GM. Anexo 1. Brasília: Ministério da Saúde; 1997.

2. Brasil. Ministério da Saúde. Programa de Agentes Comunitários de Saúde. Brasília: M inistério da Saúde; 2001.

3. Bezerra AFB, Espírito Santo ACG, Batista Filho M. Concepções e práticas do agente comunitário na atenção à saúde do idoso. Rev. Saude Publica 2005; 39(5):809-815.

4. Brasil. M inistério da Saúde. Cadernos da Atenção Programa Saúde da Família. Brasília: Ministério da Saúde; 2000.

5. Centro Estadual de Educação Profissional em Saúde Monsenhor José Luís Barbosa Cortês. M anual do Curso Técnico de ACS. Coletânea de textos módulo 1 e 2. Teresina: Centro Estadual de Educação Profissional em Saúde Monsenhor José Luís Barbosa Cortês; 2006.

6. Brasil. Portaria n ${ }^{\circ} 1.886 / \mathrm{GM} / \mathrm{MS}$ de 18 de dezembro de 1997. Aprova as Normas e Diretrizes do Programa de Agentes Comunitários de Saúde e do Programa de Saúde da Família. Diário Oficial da U nião 1997; 22 dez.

7. Brasil. M inistério da Saúde. Lei no 10507, de 10 de julho de 2002. Cria a profissão de agente comunitário de saúde e dá outras providências. Diário Oficial da União 2002; 11 jul.

8. Pereira AC. Odontologia em Saúde Coletiva. Porto Alegre: Artmed; 2003.

9. Brasil. M inistério da Saúde. Secretaria de Atenção à Saúde. Departamento de Atenção Básica. Coordenação de Saúde Bucal. Diretrizes da Política Nacional de Saúde Bucal. Brasília: M inistério da Saúde; 2004.

10. Nunes MO, Trad LB, Almeida BA, Homem CR, $\mathrm{M}$ elo $\mathrm{MCl}$. $O$ agente comunitário de saúde: construção da identidade desse personagem híbrido e polifônico. Cad Saude Publica 2002; 18(6):1639-1646.

11. Buchabqui JA, Capp E, Petuco DRS. Convivendo com Agentes de Transformação: a interdisciplinaridade no processo de ensino/aprendizado em saúde. Rev Bras Educ M ed 2006; 30(1):32-38.
12. Trad LB, Bastos ACS, Santana EM, Nunes MO. Estudo etnográfico da satisfação do usuário do Programa Saúde da Família (PSF) na Bahia. Cien Saude Colet 2002; 7(3):581-589.

13. Silva JA, Dalmaso ASW. Agente comunitário de saúde: o ser, o saber, o fazer. Rio de Janeiro: Fiocruz; 2002.

14. Ferraz $L$, Aerts DRGC. 0 cotidiano de trabalho do agente comunitário de saúde no PSF em Porto Alegre. Cien Saude Colet 2005; 10(2):346-355.

15. Giffin K, Shiraiwa T. 0 agente comunitário de saúde pública: a proposta de Manguinhos. Cad Saude Publica 1989; 5(1):24-44.

16. Levy FM, M atos PES, Tomita NE. Programa de agentes comunitários de saúde: a percepção de usuários e trabalhadores da saúde. Cad Saude Publica 2004; 20(1):197-203.

17. Fortes PAC, Spinetti SR. O agente comunitário de saúde e a privacidade das informações dos usuários. Cad Saude Publica 2004; 20(5):1328-1333.

18. Moura LFAD, Lira DM M P, M oura MS, Barros, SSLV, Lopes TSP, Leopoldino VD, Moura MDM. Apresentação do programa preventivo para gestantes e bebês. J Bras de Odontopediatr Odontol Bebê 2001; 4(17):10-14.

19. M israchi $C L$, Sáez MS. Valores, crencias y practicas populares em relación a la salud oral. Cuad M éd Soc 1989; 30(2):27-33.

20. Frazão $P, M$ arques DSC. Influência de agentes comunitários de saúde na percepção de mulheres e mães sobre conhecimentos de saúde bucal. Cien Saude Colet 2006; 11(1):131-144.

Artigo apresentado em 06/08/2007

Aprovado em 14/01/2008

Versão final apresentada em 08/02/2008 